\title{
CONDIÇÕES DE PRODUÇÃO ESCRITA EM COMANDOS DO LIVRO DIDÁTICO
} DO ENSINO FUNDAMENTAL

\section{CONDITIONS OF WRITING PRODUCTION IN THE TEXT BOOKS OF MIDDLE SCHOOL}

\author{
Layanne Barreira Lima ${ }^{1}$ \\ Ầngela Francine Fuza ${ }^{2}$
}

Resumo: Este trabalho objetiva analisar as condições de produção presentes em comandos de escrita de livro didático de Língua Portuguesa do $6^{\circ}$ ano, refletindo sobre o modo como podem interferir na escrita do aluno. Analisam-se os comandos, segundo as condições: (a) Se tenha o que dizer; (b) Se tenha uma razão para dizer; (c) Se tenha para quem dizer; (d) O locutor se constitua como tal, enquanto sujeito; (e) Se escolham as estratégias para realizar (a), (b), (c) e (d). Os resultados demonstram que as condições (a) e (e) são as mais recorrentes, enquanto (d) está presente em um único comando. Embora as condições de produção contribuam no direcionamento da escrita, possibilitando ao estudante se constituir como escritor de seus textos, em nenhum comando todas elas foram contempladas. Com isso, o aluno não sabe porque escreve e/ou para quem escreve, elaborando textos apenas para a escola.

Palavras-chave: escrita; condição de produção; livro didático.

Abstract: The present study aims at analyzing the conditions of writing production in requests for textual production in Portuguese Language textbooks for at $6^{\text {th }}$ grades, reflecting on how they might interfere with student writing. The requests for textual production are analyzed, according to the following conditions: a)"If you've got what to say", b) "If you've got a reason to say whatever you have to say" c) If you've got someone to say whatever you have to say", d) Locutor can be constituited as such and as subject who says what he says to whom he says what he has to say, e) "If you've got to choose strategies to perform (a), (b), (c) and (d)". The results show that conditions (a) and (e) are the most recurrent, while (d) is present in a single command. Although conditions of production can contribute to orientate writing, what enable the student to constitute himself as a writer of his own texts, in none request were observed all the conditions. With this, the student does not know why he writes and / or writes, writing texts only for school.

Keywords: writing; condition of production; text book.

\footnotetext{
1 Universidade Federal do Tocantins (UFT), Câmpus de Porto Nacional, Porto Nacional - TO - Brasil. layannebarreira@hotmail.com

${ }^{2}$ Universidade Federal do Tocantins (UFT), Câmpus de Porto Nacional, Porto Nacional - TO - Brasil. Professora Permanente do Programa de Pós-Graduação em Letras. angelafuza@uft.edu.br
} 


\section{Introdução}

[...] Atrás dela, no quadro-negro, eu vi decretado o fim das nossas férias [...] Estava escrito: "Redação: escrever trinta linhas sobre as férias". Eu sabia que as férias de ninguém iam ser mais as mesmas na hora que virassem redação. É simples: férias é legal, redação é chato. De repente as nossas férias ficaram silenciosas. Onde já se viu férias sem barulho? [...] eu tenho certeza de que a professora nem quer saber de verdade como foram as nossas férias. Ela quer só saber como é a nossa letra e se a gente tem jeito para escrever redação (GRIBEL, 2013, p. 8-9).

A epígrafe que abre este texto apresenta cena comum nas escolas: o professor solicita a escrita de um texto ao aluno sobre as férias. Nesse contexto, há, sim, condições de produção texto, pois há um tema sobre o qual se escreve: "as férias"; há um o objetivo de escrita: "[a professora quer] saber como é a nossa letra e se a gente tem jeito para escrever redação" e há interlocutor: a professora. No entanto, o fruto desse trabalho de escrita é uma redação, para a escola (GERALDI, 1997), a fim de que o professor avalie, sem uma finalidade real de comunicação, tornando o ato de escrever "chato", como o próprio personagem da história afirma.

Em função disso, este texto pontua que, para que o estudante efetivamente elabore uma produção textual na escola, é necessário que o educador utilize metodologias e materiais didáticos que propiciem esse trabalho e que despertem a consciência sobre a importância de se ter uma finalidade para escrever, ou seja, haja motivações reais de produção do texto e não o artificialismo, muitas vezes, apresentado em sala de aula e nos materiais didáticos.

$\mathrm{O}$ ato de escrever envolve processos e critérios de organização que preparam o sujeito para escrita. Para isso, considera-se relevante que professores e alunos conheçam as condições de produção dos enunciados, a saber: “a) Se tenha o que dizer; b) Se tenha uma razão para dizer, o que se tem a dizer; c) Se tenha para quem dizer o que se tem a dizer; d) O locutor se constitua como tal, enquanto sujeito que diz o que diz para quem diz. e) Se escolham as estratégias para realizar (a), (b), (c) e (d)" (GERALDI, 1997, p. 137).

Diante disso, esta pesquisa, vinculada ao Projeto de Pesquisa: “A escrita em contextos de ensino e de aprendizagem" (UFT), lançou um olhar cuidadoso a respeito dos comandos do livro didático do $6^{\circ}$ ano do Ensino Fundamental, com o objetivo de analisar as condições de produção escrita presentes nesse material. Especificamente, buscam-se analisar quais as condições de produção de texto são contempladas nos comandos e caracterizar de que modo isso interfere na elaboração do texto pelo estudante. 
Trata-se de um trabalho documental (LÜDKE; ANDRÉ, 1986), fundamentado teóricometodologicamente na concepção de escrita como trabalho, segundo os princípios teóricos da Linguística Aplicada e da perspectiva sócio-histórica de ensino-aprendizagem. O livro do 6. ${ }^{\circ}$ ano selecionado integra a coleção Português Linguagens, de Cereja e Cochar (2015). A escolha deste material ocorreu por haver um vasto número de comando de escrita para análise, e por ser utilizado na região de Porto Nacional e em outras localidades brasileiras. No livro, analisa-se a seção "Produção de texto", que se divide em duas partes: a primeira diz respeito ao estudo do gênero que será trabalhado, por meio de perguntas, e a segunda parte vem introduzida pelo título “Agora é a sua vez”, que concentra necessariamente o comando de escrita.

Dessa forma, considerando os objetivos propostos, na sequência, apresentam-se as teorias sobre concepções e condições de escrita. Depois, destaca-se a Metodologia da pesquisa, assim como a análise das condições de produção do texto que foram contempladas nos comandos do LD do $6^{\circ}$ ano e, por fim, a conclusão.

\section{Concepções de escrita}

Antes do surgimento da escrita, os povos se comunicavam por intermédio de pinturas e desenhos, havendo a necessidade de organizar os pensamentos e controlar o meio em que viviam, surgiu, a escrita; ela foi se desenvolvendo a medida em que as necessidades humanas foram aparecendo. Desde então, o ser humano passou a registrar suas emoções, ações e desejos por meio da grafia. É por meio da escrita que o homem defende seu ponto de vista, comunicase, tem acesso às informações e produz o conhecimento.

Com o advento da escrita na sociedade, houve uma época em que poucas pessoas podiam usufruir dela. Diferentemente dos dias atuais, em que escrever faz parte do cotidiano de todos, podendo, assim, produzir uma carta, uma mensagem via e-mail e fazer uma lista de compras. No âmbito da sala de aula, destaca-se a preocupação do aluno ao elaborar um texto; estar diante de uma folha em branco e não saber “o que dizer?", “como dizer?” e "para quem dizer?” são dúvidas constantes. Diante disso, é necessário que o professor pense nas formas de trabalho com a escrita, conhecendo as suas concepções que podem contribuir para a eficiência do trabalho do aluno ou não, dependendo de qual delas o professor utilizará. São conhecidas quatro concepções de escrita (SERCUNDES, 1997; MENEGASSI, 2016): escrita com foco na língua; escrita como dom/inspiração; escrita como consequência; escrita como trabalho. 
Na concepção foco na língua, professor e aluno estão inteiramente preocupados com as regras gramaticais, o aluno tem o cuidado em escrever corretamente e o professor se atenta em corrigir os erros de grafia presentes no texto. Conforme Menegassi (2013), antes de produzir um texto, o aluno internaliza, primeiramente, à norma padrão da escrita. Ele realiza exercício de sinais de pontuação, grafia de palavras, sobre concordância e muitos outros exercícios que fazem parte do estudo da gramática. Desse modo, imagina que só escreverá bem se tiver um domínio das regras gramaticais, sendo que a ortografia é a primeira avaliação que o professor faz em um texto. Sendo assim, o aluno, nessa concepção, preocupar-se-á apenas com a norma padrão e não com o conteúdo de seu texto, isso implica um aluno menos motivado, que não sente satisfação em escrever, pois apenas produz para ser avaliado gramaticalmente.

Na concepção de escrita como dom/inspiração, os alunos são levados a escrever seus textos, a partir de um título ou apenas de uma frase dada pelo professor, sem que haja uma atividade anterior que os ajude e os estimule na construção de seus textos (SERCUNDES, 1997, p. 95). Com isso, "O aluno é convidado a escrever sem refletir quanto às metas que deveria perseguir ou quanto à orientação argumentativa que deveria imprimir a seu texto" (VAL, 2003, p. 133). O aluno pode sentir-se desestimulado, pois, além de não haver uma discussão prévia sobre o que irá escrever, também não há uma finalidade e um objetivo definido, que o estimule na construção do trabalho.

A concepção de escrita como consequência, por sua vez, pauta-se em "atividades prévias" (SERCUNDES, 1997), como: discussões a respeito de um determinado tema, debates sobre alguma imagem ou filme assistido dentro da sala de aula, uma leitura, ou até mesmo uma visita em algum ponto turístico da cidade. Para tanto, “cada um desses itens será um pretexto para se realizar um trabalho escrito" (SERCUNDES, 1997, p. 78). Após as contribuições das atividades prévias, o aluno é levado a produzir seu texto, que será entregue ao professor e não será reescrito pelo aluno, apenas avaliado com uma nota, pois: “A produção de texto nessa concepção é vista apenas como a finalização de um trabalho. A falta de continuidade da atividade desmotiva o aluno, pois não encontra uma razão significativa para escrever” (ESPER; MENEGASSI, 2011, p. 10).

A concepção de escrita como trabalho é conhecida, na visão de Menegassi (2013), como aquela que realmente "dá trabalho", pois o aluno deve preparar, construir, revisar, reescrever e avaliar seu texto. Assim como na escrita como consequência, nesta concepção, empregam-se “atividades prévias" (SERCUNDES, 1997), ou seja, há uma preparação antes que o aluno comece a escrita de seu texto, podendo ser uma discussão a respeito do tema proposto pelo 
professor, uma leitura prévia, um filme e outros, contudo, "as atividades prévias funcionam como um ponto de partida para desencadear uma proposta de escrita" (MENEGASSI, 2016, p. 196). A partir desse preparo, o aluno poderá começar a escrever seu texto, pois as atividades prévias servem como base para escrita: “A produção, nesse caso, surge de um processo contínuo de ensino/aprendizagem" (SERCUNDES, 1997, p. 83).

A escrita é tida como trabalho, perpassando etapas, como o planejamento, a escrita, a revisão e a reescrita. Nesse sentido, com base em Geraldi (1997), o texto, visto como unidade de ensino, deve ser entendido como local de diálogo com outros textos, produzidos anteriormente, dando origem a novos discursos.

O professor é um dos interlocutores mais próximos dos alunos, não é apenas um avaliador nessa concepção. O visto e a nota não são mais o produto final da produção do aluno, que passa a ser revisada; após essa revisão, feita pelo professor, surge a etapa seguinte que é a reescrita, fundamental para o trabalho da produção textual.

De acordo com Fuza e Menegassi (2012, p. 42), "a produção de texto é concebida como um trabalho, fazendo com que o professor atue por meio de diversos recursos, auxiliando o aluno durante o processo de revisão e rescrita, por intermédio de intervenções realizadas no seu texto". Dessa forma, a intervenção do professor nesse processo é de grande importância, pois ele possui o papel de mediador entre o aluno e o texto. Neste mesmo sentido, Menegassi (2016, p. 196) comenta que "a escrita é um trabalho organizado em sala de aula pelo professor e produzido pelo aluno em conjunto com esse docente, não apenas um texto a ser entregue”. Tendo em vista que a escrita não é um produto, mas, sim um processo, Menegassi (2016) traz algumas ideias centrais sobre essa concepção:

- O texto produzido segue um processo que deve ser conhecido pelo professor;

- O processo de produção de textos é complexo e apresenta-se em etapas;

- Os aspectos que envolvem o processo de escrita devem ser conhecidos;

- Conhecer as especificidades da organização do texto a ser trabalhado;

- Considerar que a multiplicidade de textos implica variados objetivos e suportes textuais, circulações diferenciadas e suas relações com conteúdos escolares diferentes, em interdisciplinaridade constante na sala de aula;

- Desenvolver no aluno a habilidade de analisar consciente e reflexivamente o próprio texto;

- Levar o aluno a compreensão do funcionamento da língua escrita nas suas situações comunicativas diferenciadas na sociedade;

- Desenvolver no aluno a capacidade de se assumir como autor, como sujeito do seu dizer;

- Definir objetivos claros para a escrita dos textos, com finalidade marcada;

- Definir que o leitor do texto é elemento primordial para sua execução.

(MENEGASSI, 2016, p. 200-202).

Dessa forma, todas essas ideias e objetivos sobre a concepção de escrita como trabalho demarcam que o aluno entenderá a escrita como um processo que é definido por condições reais 
de produção, pois ele saberá o que escrever, para quem escrever, para quê escrever, ou seja, estará consciente das condições de produção dos enunciados.

Segundo Moterani e Menegassi (2013, p. 219), "O ato de produzir um texto revela que o aluno agiu ativamente perante um comando de uma produção textual, proposto pelo professor". Dessa forma, cabe observar nos comandos, estabelecidos pelo professor, ou pelo livro didático, as condições de produção do texto: “O que dizer?”; “Qual a razão para dizer?”, "Para quem dizer?" "Qual a posição do autor?” e “Como dizer?”. Para que um texto se torne completo, é preciso que nos comandos de produção dos alunos, estejam marcadas todas elas: "na sala de aula, o professor deve apresentar, no próprio comando de produção de texto, todas essas condições para direcionar o aluno durante todas as etapas da escrita" (MOTERANI; MENEGASSI 2013, p. 219). Conforme Geraldi (1997), as condições de produção são definidas em:
a) Se tenha o que dizer;
b) Se tenha uma razão para dizer, o que se tem a dizer;
c) Se tenha para quem dizer o que se tem a dizer;
d) O locutor se constitua como tal, enquanto sujeito que diz o que diz para quem diz.
e) Se escolham as estratégias para realizar (a), (b), (c) e (d).
(GERALDI, 1997, p. 137).

A condição, “O que dizer?”, aborda o assunto, o tema sobre o qual o aluno irá discutir em seu texto. A segunda condição, “Qual a razão para dizer?”, trata da finalidade da produção, essa etapa faz com que o aluno se sinta motivado a executar seu trabalho, a ausência da finalidade, permite que a produção seja vista como mais uma tarefa que deve ser cumprida. Sobre este aspecto, Pereira (2004, p. 103) menciona que "se o estudante não consegue perceber que há boas razões para escrever, fatalmente se sentirá mais inibido e desmotivado".

De acordo com Fuza e Menegassi (2008), após análise de comandos de escrita de livros didáticos, há poucas finalidades para o aluno produzir seu texto, sendo que a problemática maior reside no fato de a maioria dos comandos não apresentar uma finalidade real de escrita que valoriza a realidade do aluno, que faz com que a produção ultrapasse o contexto escolar. Geralmente, o aluno escreve com a finalidade de alguém ler seu texto (professor ou colega), com a finalidade de expor o texto em um painel, confundindo-se finalidade e meio de circulação do texto. Para os autores (2008, p. 325), “a exposição dos textos que terminam em um painel da escola, [faz] com que muitos alunos não se sintam motivados a compartilhar suas experiências [...] com outros interlocutores".

Geraldi (2006), em seu livro "O texto na sala de aula", afirma que, na condição: "para quem dizer?", os alunos produzem para o professor "(único leitor, quando lê os textos). A 
situação da língua é, pois, artificial. Afinal, qual a graça em escrever um texto que não será lido por ninguém ou será lido apenas por uma pessoa?” (GERALDI, 2006, p. 65).

Um dos motivos que leva o aluno a não escrever seu texto, ou escrevê-lo de qualquer forma é o fato de não haver um alguém a quem se destina o seu texto. Geraldi (2006) propõe aos textos dos alunos outros destinos, que não sejam o cesto de lixo ou as mãos do professor, como a produção de livros, com os textos dos próprios alunos; o jornal da turma ou, até mesmo, a publicação em jornais do próprio município. Nesse mesmo sentido, Pereira (2004) postula a necessidade de ampliação do leque de interlocutores para um texto.

Na condição: "Qual a posição do autor?”, o autor vai assumir o papel de sujeito, sendo responsável pelo que diz. Esse sujeito, como menciona Geraldi (1997, p. 20), "ao mesmo tempo em que repete atos e gestos, constrói novos atos e gestos, num movimento histórico no qual repetição e criação andam sempre juntas". Verifica-se que o sujeito, ao construir seu texto, já tem conhecimento de outros textos anteriormente. Ou seja, para produzir o seu discurso, é preciso que se tenha conhecimento de outros discursos anteriores, estabelecendo o diálogo entre eles.

A condição: “Como dizer?", diz respeito às estratégias que serão utilizadas, os gêneros discursivos que serão trabalhados na produção dos textos. Sobre isso, Val (2003, p. 129) afirma que "produzir um texto escrito implica escolher um determinado gênero discursivo e essa escolha se faz em função de para que se escreve, para quem se escreve, em que esfera e sobre que suporte deverá circular o texto produzido".

Por meio de uma visão de escrita como trabalho, considera-se que todo texto, a fim de que seja produzido, necessita de condições claras de produção. Nesse sentido, será que os materiais didáticos apresentam essas condições em seus comandos de escrita? Como a presença delas, ou não, pode interferir no texto do aluno? Essas questões serão observadas no decorrer da análise neste texto.

\section{0 material didático analisado}

Esta pesquisa, fundamentada teórico-metodologicamente na concepção de escrita como trabalho, segundo os princípios teóricos da Linguística Aplicada e da perspectiva sóciohistórica de ensino-aprendizagem, tem o objetivo de analisar as condições de produção escrita presentes nos comandos do LD do $6^{\circ}$ ano. Trata-se de estudo documental (LÜDKE; ANDRÉ (1986), já que o objeto de estudo é o material didático, considerado documento público. 
A pesquisa escolheu a coleção Português Linguagens, de Cereja e Cochar, do 6. ${ }^{\circ}$ ano $9 .^{\circ}$ ano, selecionando, especificamente, o livro do $6 .^{\circ}$ ano, tendo em vista o vasto número de comandos de escrita para análise. A escolha por esse material ocorreu, pois é utilizado na região de Porto Nacional e em várias regiões do Brasil.

Para analisar o LD do $6 .^{\circ}$ ano, de modo a interpretar seus dados, como aporte teóricometodológico, parte-se das condições de escrita, apresentadas, principalmente por Geraldi (1997, p. 137): “a) Se tenha o que dizer” [temática]; “b) Se tenha uma razão para dizer o que se tem a dizer" [finalidade]; “c) Se tenha para quem dizer o que se tem a dizer" [interlocutor]; "d) O locutor se constitua como tal, enquanto sujeito que diz o que diz para quem diz" [posição social do produtor];"e)Se escolham as estratégias para realizar (a), (b), (c) e (d)" [gênero].

No LD, observou-se a seção "Produção de texto" que, segundo o Manual do Professor (CEREJA; COCHAR; 2015), aborda diferentes gêneros. É uma seção que "procura manter um diálogo efetivo com o tema da unidade e com os textos estudados nos capítulos" (CEREJA; COCHAR; 2015, p. 300). É dividida em duas partes: na primeira, há um estudo do gênero, por meio de perguntas e, na segunda parte, introduzida pelo título "Agora é a sua vez", solicita-se a produção do texto pelo aluno. O foco desta pesquisa recai na análise desta última parte, já que é o momento efetivamente do comando de escrita.

O livro apresenta quatro unidades, com três capítulos cada (Cf. Quadro 1).

\begin{tabular}{|c|c|}
\hline \multicolumn{2}{|c|}{ Quadro1. Unidades do livro didático do $6^{\circ}$ ano } \\
\hline UNIDADES & CAPÍTULOS \\
\hline \multirow[t]{3}{*}{ 1. No mundo da fantasia } & 1- Era uma vez \\
\hline & 2- Pato aqui, pato acolá \\
\hline & 3- Ó princesa! Jogue-me suas... \\
\hline \multirow[t]{3}{*}{ 2. Crianças } & 1- $\quad$ O fazendeiro da cidade \\
\hline & 2- $\quad$ Entre irmãos \\
\hline & 3- Ensaios da vida \\
\hline \multirow[t]{3}{*}{ 3. Descobrindo quem sou eu } & 1- No frescor da Inocência \\
\hline & 2- O preço de pensar diferente \\
\hline & 3- O eu que existe em mim \\
\hline \multirow[t]{3}{*}{ 4. Verde, adoro ver-te } & 1- $\quad$ Asas da Liberdade? \\
\hline & 2- A natureza pede socorro \\
\hline & 3- Natureza no museu \\
\hline
\end{tabular}

Fonte: Elaboração das autoras.

Diante do exposto, fez-se a análise das condições dos 14 comandos de escrita (Cf. Quadro2): 
Quadro 2. Levantamento das condições de produção nos comandos dentro das unidades.

\begin{tabular}{|c|c|c|c|c|c|}
\hline \multicolumn{6}{|c|}{ [Unidade 1- No mundo da fantasia] } \\
\hline Comandos & $\begin{array}{c}\text { Tema } \\
\text { (a. Se tenha o que dizer) }\end{array}$ & \begin{tabular}{|c|} 
Finalidade \\
(b. Se tenha uma razão \\
para dizer)
\end{tabular} & $\begin{array}{l}\text { Interlocutor } \\
\text { (c.Se tenha } \\
\text { para quem } \\
\text { dizer) }\end{array}$ & $\begin{array}{l}\text { Posição do } \\
\text { sujeito } \\
\text { produtor } \\
\text { (d. locutor se } \\
\text { constitua } \\
\text { como tal) }\end{array}$ & $\begin{array}{c}\text { Gênero } \\
\text { e. Se } \\
\text { escolham as } \\
\text { estratégias } \\
\text { para realizar } \\
\text { (a), (b), (c) e } \\
\text { (d) }\end{array}$ \\
\hline $\begin{array}{l}\text { Comando1 } \\
\text { (cap. 1) }\end{array}$ & $\begin{array}{l}\text { "Uma história tradicional, } \\
\text { ocorrida no passado". "Uma } \\
\text { história ocorrida nos dias } \\
\text { atuais". }\end{array}$ & Publicar em livro & $\mathrm{X}$ & $\mathrm{X}$ & $\begin{array}{l}\text { Contos } \\
\text { maravilhosos }\end{array}$ \\
\hline $\begin{array}{l}\text { Comando } 2 \\
\text { (cap. 2) }\end{array}$ & 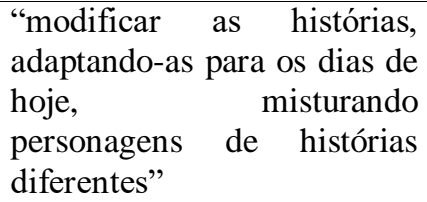 & Publicar em livro & $\begin{array}{l}\text { Colegas de } \\
\text { classe e de } \\
\text { outras; pais e } \\
\text { convidados. }\end{array}$ & $\mathrm{X}$ & $\begin{array}{l}\text { Contos } \\
\text { maravilhosos }\end{array}$ \\
\hline $\begin{array}{l}\text { Comando } 3 \\
\text { (cap. } 3 \text { ) }\end{array}$ & $\begin{array}{l}\text { "Você deverá contar histórias } \\
\text { empregando a norma-padrão } \\
\text { informal". }\end{array}$ & $\begin{array}{l}\text { Gravar a contação de } \\
\text { histórias. }\end{array}$ & \begin{tabular}{ll|}
$\begin{array}{l}\text { Colegas } \\
\text { classe. }\end{array}$ & de \\
\end{tabular} & $\mathrm{X}$ & $\begin{array}{l}\text { O conto } \\
\text { maravilhoso }\end{array}$ \\
\hline \multicolumn{6}{|c|}{ [Unidade 2- Crianças] } \\
\hline Comandos & Tema & Finalidade & Interlocutor & $\begin{array}{l}\text { Papel do } \\
\text { sujeito- } \\
\text { escritor }\end{array}$ & Gênero \\
\hline $\begin{array}{l}\text { Comando } \\
4 \text { (cap. } 1)\end{array}$ & $\begin{array}{l}\text { "Transformar a piadinha em } \\
\text { História em quadrinhos". }\end{array}$ & $\begin{array}{lrr}\text { Expor } & \text { na } & \text { mostra } \\
\text { Quadrinhos: } & e u \\
\text { também } & \text { faço!'”ou } \\
\text { expor no } & \text { mural da } \\
\text { escola. } & & \\
\end{array}$ & \begin{tabular}{ll|}
$\begin{array}{l}\text { Colegas } \\
\text { classe }\end{array}$ & de \\
\end{tabular} & $\mathrm{X}$ & $\begin{array}{l}\text { História em } \\
\text { Quadrinhos }\end{array}$ \\
\hline $\begin{array}{l}\text { Comando } \\
\text { 5(cap. 2.) }\end{array}$ & $\begin{array}{l}\text { "Criar história em } \\
\text { quadrinhos, procurando } \\
\text { empregar: balões e letras de } \\
\text { diferentes etc." }\end{array}$ & $\begin{array}{l}\text { Expor no mural da } \\
\text { classe; expor na mostra } \\
\text { Quadrinhos: } \quad \text { eu } \\
\text { também faço!" }\end{array}$ & \begin{tabular}{ll|}
$\begin{array}{l}\text { Colegas de } \\
\text { classe }\end{array}$ & \\
\end{tabular} & $\mathrm{X}$ & $\begin{array}{l}\text { História em } \\
\text { Quadrinhos e } \\
\text { cartazes }\end{array}$ \\
\hline $\begin{array}{l}\text { Comando } \\
\text { 6(cap. 3) }\end{array}$ & $\begin{array}{l}\text { "esboçaras personagens } \mathrm{e} \\
\text { escrever suas falas e os } \\
\text { pensamentos, } \\
\text { onomatopeias e interjeições". }\end{array}$ & $\begin{array}{lr}\text { Expor na } & \text { mostra } \\
\text { Quadrinhos: } & \text { eu } \\
\text { também faço!" } & \end{array}$ & $\mathrm{X}$ & Argumentista & $\begin{array}{l}\text { História em } \\
\text { Quadrinhos }\end{array}$ \\
\hline \multicolumn{6}{|c|}{ [Unidade 3- Descobrindo quem sou eu] } \\
\hline Comandos & Tema & Finalidade & Interlocutor & $\begin{array}{l}\text { Papel do } \\
\text { sujeito- } \\
\text { escritor }\end{array}$ & Gênero \\
\hline $\begin{array}{l}\text { Comando } 7 \\
\text { (cap. } 1)\end{array}$ & $\begin{array}{l}\text { "começar o relato dizendo } \\
\text { seu nome e sua idade e } \\
\text { descrevendo como você é } \\
\text { fisicamente; Conte sobre sua } \\
\text { família; sobre seus gostos". }\end{array}$ & $\begin{array}{l}\text { Publicar em livro ou } \\
\text { em um blog. }\end{array}$ & $\begin{array}{l}\text { Colegas } \\
\text { classe de } \\
\text { outras classes, } \\
\text { professores, } \\
\text { pais, amigos e } \\
\text { internautas. }\end{array}$ & $\mathrm{X}$ & $\begin{array}{l}\text { Relato } \\
\text { pessoal }\end{array}$ \\
\hline $\begin{array}{l}\text { Comando } 8 \\
\text { (cap. } 2)\end{array}$ & $\begin{array}{l}\text { "relatando fatos do passado, } \\
\text { como o nascimento de um } \\
\text { irmão, um encontro } \\
\text { inesperado, o primeiro dia na } \\
\text { escola." }\end{array}$ & $\begin{array}{l}\text { Publicar em livro ou } \\
\text { blog, a ser produzido } \\
\text { no capítulo Intervalo. }\end{array}$ & \begin{tabular}{ll|}
$\begin{array}{l}\text { Colegas de } \\
\text { classe }\end{array}$ & \\
\end{tabular} & $\mathrm{X}$ & Diário \\
\hline $\begin{array}{l}\text { Comando } 9 \\
\text { (cap. 3) }\end{array}$ & 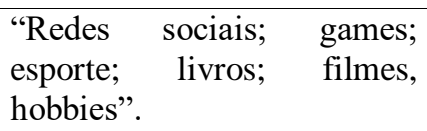 & $\begin{array}{l}\text { Publicar livro ou blog a } \\
\text { ser montado no projeto } \\
\text { do capítulo intervalo. }\end{array}$ & $\begin{array}{l}\text { envie-o(s) a } \\
\text { um } \\
\text { destinatário. }\end{array}$ & $\mathrm{X}$ & $e$-mails \\
\hline
\end{tabular}




\begin{tabular}{|c|c|c|c|c|c|}
\hline $\begin{array}{l}\text { Comando } 10 \\
\text { (cap.3) }\end{array}$ & $\begin{array}{l}\text { "Produzam um ou mais } \\
\text { comentários a propósito de } \\
\text { um assunto do interesse de } \\
\text { todos". }\end{array}$ & $\mathrm{X}$ & $\mathrm{X}$ & $\mathrm{X}$ & $\begin{array}{l}\text { Comentário } \\
\text { em blog ou } \\
\text { site. }\end{array}$ \\
\hline \multicolumn{6}{|c|}{ [Unidade 4-Verde, adoro ver-te] } \\
\hline Comandos & Tema & Finalidade & Interlocutor & $\begin{array}{l}\text { Papel do } \\
\text { sujeito- } \\
\text { escritor }\end{array}$ & Gênero \\
\hline $\begin{array}{l}\text { Comando } 11 \\
\text { (cap. 1) }\end{array}$ & $\begin{array}{l}\text { "Zoológico; ecossistema; } \\
\text { animais extintos". }\end{array}$ & $\begin{array}{l}\text { Publicar em blog } \\
\text { coletivo da classe ou } \\
\text { enviar a um fórum de } \\
\text { debates na internet. }\end{array}$ & $\begin{array}{l}\text { Para jovens e } \\
\text { adultos. }\end{array}$ & $\mathrm{X}$ & $\begin{array}{l}\text { Artigo de } \\
\text { opinião }\end{array}$ \\
\hline $\begin{array}{l}\text { Comando } 12 \\
\text { (cap. 2) }\end{array}$ & $\begin{array}{l}\text { "Direito dos animais; maus- } \\
\text { tratos e atos cruéis; } \\
\text { Substituição de animais nos } \\
\text { testes de laboratório". }\end{array}$ & $\begin{array}{l}\text { Enviara um jornal da } \\
\text { cidade ou a um fórum } \\
\text { de debates de um dos } \\
\text { provedores da internet. }\end{array}$ & \begin{tabular}{|lr} 
Colegas & de \\
classe, e de \\
outros anos. \\
Por \\
familiares; \\
amigos r e \\
visitantes da \\
mostra.
\end{tabular} & $\mathrm{X}$ & $\begin{array}{l}\text { Artigo de } \\
\text { opinião }\end{array}$ \\
\hline $\begin{array}{l}\text { Comando } \\
\text { 13(cap. 3) }\end{array}$ & $\begin{array}{l}\text { "Desmatamento; Poluição } \\
\text { dos rios, lagos e represas; } \\
\text { Poluição do ar; Poluição } \\
\text { sonora; Poluição visual; O } \\
\text { lixo; Extinção de animais; } \\
\text { Aquecimento global". }\end{array}$ & $\mathrm{X}$ & A classe & $\mathrm{X}$ & $\begin{array}{l}\text { Exposição } \\
\text { Oral }\end{array}$ \\
\hline $\begin{array}{l}\text { Comando } 14 \\
\text { (cap. 3) }\end{array}$ & $\begin{array}{l}\text { "Não desperdiçar água; } \\
\text { Economizar energia; Jogar } \\
\text { lixo no lixo; Preservar grama; } \\
\text { Separar o lixo". }\end{array}$ & $\begin{array}{l}\text { Expor nas paredes de } \\
\text { toda escola ou em um } \\
\text { mural situado em um } \\
\text { local de grande } \\
\text { circulação de pessoas. }\end{array}$ & \begin{tabular}{|l|} 
Alunos, \\
professores, \\
funcionários \\
da escola, \\
familiares \\
\end{tabular} & $\mathrm{X}$ & Cartaz \\
\hline
\end{tabular}

Fonte: Elaboração das autoras.

O levantamento, realizado nos 14 comandos de escrita, possibilitou constatar as seguintes recorrências de cada condição de produção:

Quadro 3. Recorrência de cada condição de produção

\begin{tabular}{|l|c|}
\hline \multicolumn{1}{|c|}{ CONDIÇÕES } & $\begin{array}{c}\text { QUANTAS VEZES ESTEVE } \\
\text { PRESENTE NOS COMANDOS }\end{array}$ \\
\hline A. Se tenha o que dizer (tema) & 14 \\
\hline B. Se tenha uma razão para dizer (finalidade) & 12 \\
\hline C. Se tenha para quem dizer(interlocutor) & 11 \\
\hline D. Locutor se constitua como tal (papel do sujeito - escritor) & 1 \\
\hline E. Se escolham as estratégias para realizar (a), (b), (c) e (d). (gênero) & 14 \\
\hline
\end{tabular}

Fonte: Elaboração das autoras.

Como revela o Quadro 3, a condição que menos apareceu nos comandos foi “d) Locutor se constitua como tal (papel do sujeito-escritor)", sendo encontrada apenas no sexto comando (Cf.Quadro 3). Duas condições se destacaram nos comandos observados: "a) Se tenha o que dizer (tema)" e "e) Se escolham as estratégias para realizar (a), (b), (c) e (d) (gênero)", pois 
foram encontras em todos os 14 comandos do LD. Depois, vem a finalidade com 12 ocorrências e interlocutor, com 11.

\section{Os comandos de escrita do livro didático}

Esta seção está organizada de acordo com cada condição de produção: quanto ao tema; quanto à finalidade; quanto ao interlocutor; quanto ao papel social do produtor e quanto ao gênero. Cada uma delas é discutida e expõe-se um exemplo de comando para ilustrá-la.

\subsection{Quanto aos temas abordados}

Dentro de cada unidade, foram verificados os temas a serem produzidos pelo aluno (Cf. Quadro 4).

Quadro 4. Levantamento dos temas solicitados nos comandos.

\begin{tabular}{|c|c|}
\hline Unidade & $\begin{array}{l}\text { - "Produzir uma história tradicional, ocorrida no passado. Uma história ocorrida nos dias atuais". } \\
\text { - "modificar as histórias, adaptando-as para os dias de hoje, misturando personagens de histórias } \\
\text { diferentes". } \\
\text { - "Contar histórias empregando a norma-padrão informal. }\end{array}$ \\
\hline $\begin{array}{c}\text { Unidade } \\
2\end{array}$ & $\begin{array}{l}\text { - "Transformar a piadinha em História em quadrinhos". } \\
\text { - "Criar história em quadrinhos, procurando empregar: balões e letras de diferentes tipos, tamanhos } \\
\text { e cores, legenda, onomatopeias e interjeições. } \\
\text { - "Esboçar personagens e escrever suas falas e os pensamentos, as onomatopéias e interjeições". }\end{array}$ \\
\hline $\begin{array}{c}\text { Unidade } \\
3\end{array}$ & $\begin{array}{l}\text { - "Começar o relato dizendo seu nome e sua idade e descrevendo como você é físicamente; Conte } \\
\text { sobre sua família; sobre seus gostos." } \\
\text { - "Relatando fatos do passado, como o nascimento de um irmão, um encontro inesperado, o } \\
\text { primeiro dia na escola." } \\
\text { - "Redes sociais; games; esporte; livros; filmes, hobbies". } \\
\text { - "Produzam um ou mais comentários a propósito de um assunto do interesse de todos". }\end{array}$ \\
\hline $\begin{array}{c}\text { Unidade } \\
4\end{array}$ & $\begin{array}{l}\text { - "Zoológico; ecossistema; animais extintos". } \\
\text { - "Direito dos animais; maus-tratos e atos cruéis; Substituição de animais nos testes de laboratório". } \\
\text { - "Desmatamento; Poluição dos rios, lagos e represas; Poluição do ar; Poluição sonora; Poluição } \\
\text { visual; O lixo; Extinção de animais; Aquecimento global". } \\
\text { - "Não desperdiçar água; economizar energia; Jogar lixo no lixo; Preservar grama; Separar o lixo". }\end{array}$ \\
\hline
\end{tabular}

Fonte: Elaboração das autoras.

Na primeira unidade, os três capítulos tratam do mesmo gênero "contos maravilhosos", porém não possuem o mesmo tema, somente os dois primeiros capítulos, que os temas abordados se coincidem; na primeira proposta, o aluno escreverá uma história tradicional, ocorrida no passado, e uma história, ocorrida nos dias atuais; no segundo capítulo, o aluno escreverá o texto, modificando as histórias, adaptando-as para os dias de hoje. Na segunda unidade, há, nos três capítulos, o mesmo gênero "História em Quadrinhos", sendo que os temas são parecidos, como a criação de personagens e falas. Na terceira unidade, os temas são diversos 
e diferentes, pois tratam de gêneros totalmente diferentes dos demais. Na quarta unidade, apesar dos gêneros serem diferentes como "artigo de opinião, exposição oral, cartaz", os temas são parecidos, pois todos discutem a respeito do meio ambiente.

Os temas que são cobrados para a produção dos textos, são vistos e estudados antes dos comandos, com isso, os alunos possuem base para escrita.

Destaca-se, aqui, o primeiro comando do LD para ilustrar a condição: a) Se tenha o que dizer (Tema):

\section{AGORA É A SUA VEZ}

Há, a seguir, três propostas de produção de textos. Conforme a orientação de seu professor, produza os contos maravilhosos individualmente ou em grupo. Eles serão publicados depois em um livro de contos que fará parte da mostra "Histórias de hoje e sempre", proposta no capítulo "Intervalo".

1. Reúna-se com seus colegas de grupo para, juntos, planejarem e escreverem um conto maravilhoso. Vocês podem produzir dois tipos de conto:

- Uma história tradicional, ocorrida no passado, com as típicas personagens de contos maravilhosos.

- Uma história ocorrida nos dias atuais. Nesse caso, trabalhem com outros tipos de personagem, como, por exemplo, um garoto corajoso e destemido, uma mocinha distraída que adora ler, um cantor de rap, um esqueitista, uma avó moderna... ou um herói às avessas, isto é, atrapalhado, que tem medo das baratas, etc. E, para o vilão, escolham uma feiticeira muito má, uma bruxa moderna, que substituiu a vassoura por uma moto aquática, etc.

2. Escolha uma personagem de conto maravilhoso de que você goste muito (um mágico, uma fada, um super-herói, etc.) e crie uma história em que ela se envolva com outras personagens de contos maravilhosos, como, por exemplo, príncipes, reis, bruxas, ogros, gigantes, dragões, gênios, etc. Siga as instruções da proposta anterior.

3. Dê asas à imaginação e crie livremente um conto maravilhoso.

(CEREJA; COCHAR; 2015, p.21).

No comando ilustrado, são solicitadas três propostas de produção de textos. Os temas se localizam na primeira proposta, sendo dois tipos de temas. O primeiro, uma história tradicional, ocorrida no passado, com as típicas personagens de contos maravilhosos; e o segundo, uma história ocorrida no presente, trabalhando com outros tipos de personagens, como um garoto corajoso e destemido, uma mocinha distraída que adora ler etc. O tema é importante no comando para a produção do texto, pois ele situa o aluno no momento da escrita e delimita o que irá ser produzido.

Antes do comando, há atividades prévias, como textos, filmes e atividades de compreensão e interpretação, preparando o aluno para o exercício da escrita. Esse comando, assim como os demais do livro didático, é dividido em seções. A primeira seção é chamada “Agora é a sua vez", nessa, tem as propostas de produção, bem como o gênero que o aluno irá trabalhar, a finalidade, o tema e o interlocutor. A segunda seção tem por título "Planejamento do texto", sendo que uma das etapas da concepção de escrita, depois das atividades prévias é o 
planejamento, nessa seção, o aluno saberá de que forma escreverá seu texto. A última seção é chamada de "Revisão e Reescrita", fases contempladas na concepção de escrita como trabalho, sendo importantes para o aluno, pois sabendo delas e colando-as em prática, o aluno verá a escrita não como um produto, mas sim, como um processo.

\title{
3.2 Quanto às finalidades de escrita
}

As finalidades que foram identificadas nos comandos: "Publicar em livro"; "Gravar a Contação de histórias"; "Expor na mostra Quadrinhos: eu também faço!" ou "expor no mural da escola"; "Publicar livro ou blog a ser montado no projeto do capítulo intervalo"; "Publicar em blog coletivo da classe ou enviar a um fórum de debates na internet"; "Enviar a um jornal da cidade ou a um fórum de debates de um dos provedores da internet"; "Expor nas paredes de toda escola ou em um mural situado em um local de grande circulação de pessoas".

Destaca-se o quinto comando do LD para ilustrar essa condição:

\begin{abstract}
AGORA É A SUA VEZ
Crie uma história em quadrinhos, procurando empregar alguns dos recursos estudados: balões e letras de diferentes tipos, tamanhos e cores, legendas, onomatopeias e interjeições. Para isso, em seu caderno ou em uma folha de papel sulfite, desenhe os quadrinhos e as cenas da história. Use legendas, se necessário, e balõezinhos com a fala das personagens. Dê título a história, incorporando- o ao primeiro quadrinho. Antes de pintar os desenhos, revise sua história em quadrinhos, observando os critérios para revisão e reescrita apontados no capitulo 1 desta unidade, na página 90. Ao finalizar o trabalho, troque sua história em quadrinhos com as dos colegas ou exponha-a no mural da classe. Depois guarde-a para expor na mostra 'Quadrinhos eu também faço', proposta no capitulo 'Intervalo' desta unidade.
\end{abstract}

(CEREJA; COCHAR; 2015, p. 107- 108).

Nesse comando, o aluno irá criar uma história em quadrinhos, com a finalidade "exponhaa no mural da classe. Depois guarde-a para expor na mostra 'Quadrinhos eu também faço!'”. A presença da finalidade nos comandos de escrita é importante, pois com ela o aluno encontra boas razões para escrever, sentindo-se motivado. Autor e autor (ano), analisando os livros didáticos, perceberam que há poucas finalidades nos comandos de escrita, sendo que o maior problema encontrado nesses comandos foi a ausência de uma finalidade real, que ultrapasse os muros da escola. As finalidades observadas nos comandos são confundidas com a circulação, como expor o texto em um painel.

Observando os comandos do livro didático do $6^{\circ}$ ano, há a presença da ideia de expor as produções dos alunos em uma mostra. Essa mostra foi observada no final de algumas unidades, por exemplo, a finalidade do comando ilustrado acima é “expor na mostra Quadrinhos 'Eu também faço!"”, essa ideia é observada no final da segunda unidade, no capítulo denominado 
como Intervalo. Nele, os alunos, juntamente com os professores, organizam todas as produções, realizadas durante a unidade, para serem expostas em algum lugar da escola; os textos são colocados em cartazes, em mesas, paredes, murais ou varais. Os alunos também podem montar peças teatrais, fantasiarem de acordo com os personagens das histórias em quadrinhos. As pessoas convidadas para essa mostra são os professores, pais e comunidade.

Percebe-se, que os alunos utilizarão a própria escola para divulgar seus trabalhos, nessa ideia a produção do aluno, ultrapassa as quatro paredes da sala de aula, alcançando o ambiente escolar, de modo geral. No entanto, não há uma finalidade de cunho social que possibilitasse, por exemplo, atingir outros espaços, como sua própria casa ou outros interlocutores.

Antes da produção da história em quadrinhos, os alunos já haviam estudado alguns recursos que são empregados na HQ, como: balões, letras de diferentes formas, legendas, onomatopeias e interjeições, essa é considerada como uma atividade prévia, que prepara os alunos para a produção, a partir disso, produzem sua história, que será revisada e reescrita. Os interlocutores serão os próprios colegas e a finalidade será a mostra “Quadrinhos eu também faço!”

\subsection{Quanto aos interlocutores}

Os interlocutores, marcados nos comandos analisados, foram: "Colegas de classe e de outras; pais e convidados"; “Colegas de classe”; "Qualquer destinatário”; “Alunos, professores, funcionários da escola, familiares". Segundo Franzoi (2009, p. 35) o locutor pode ser externo ou interno: "[...] externo se refere ao interlocutor que pertence ao contexto social do locutor, apresentando-se como real, virtual ou superior. O outro interno, ao próprio interlocutor que cada indivíduo possui dentro de si próprio".

$\mathrm{O}$ interlocutor real é aquele que tem um contato direto com o locutor, como exemplo o professor, com o qual o aluno tem um contanto físico. Além desse interlocutor real, também há o outro/real/externo, aquele que é presente, que está próximo, mas não se encontra no momento da produção, por exemplo, o coordenador da escola, está no mesmo ambiente que o aluno locutor, mas, não está no momento da escrita desse aluno. Um outro interlocutor é o virtual, que não está presente fisicamente. O interlocutor interno é o próprio locutor, que se comunica consigo mesmo.

Para verificar os interlocutores encontrados destaca-se o oitavo comando do LD: 


\section{AGORA É A SUA VEZ}

Escreva uma página de diário, relatando fatos marcantes ou diferentes que você vivenciou recentemente. Ou relatando fatos do passado, como o nascimento de um irmão, um encontro inesperado, o primeiro dia na escola, uma surpresa agradável, a alegria de ganhar um animal de estimação, uma viagem ou um passeio inesquecível, etc.

Como o diário costuma ser íntimo, decida se você quer ou não tornar público o seu texto. Se sim, quando terminar de escrevê-lo, escolha um(a) colega da classe com quem tenha mais intimidade e troquem de caderno: você será o leitor da página de diário que ele(a) escreveu, e ele (a) será o leitor de seu texto.

Depois, passe sua página de diário a limpo e guarde-a para integrar o livro ou blog a ser produzido no capítulo Intervalo desta unidade.

(CEREJA; COCHAR; 2015, p.165).

O único locutor encontrado nessa condição foi o "colega de classe", o aluno escreverá uma página de diário para ser lido, por seu colega, esse tipo de locutor é o locutor real, que está presente no momento da produção junto ao locutor. Na maioria das vezes, o único leitor do texto do aluno, será o professor, que apenas irá ler, corrigir e avaliar. O professor deve estar ciente de que, além de seu papel como interlocutor mais próximo, os alunos deverão possuir outros interlocutores. Com isso, eles produzirão melhor os seus textos, sabendo da presença de mais interlocutores, que irão conhecer seus trabalhos.

Aqui a concepção de escrita é a escrita como trabalho, pois, além das atividades prévias, que servem como base para a escrita, o ato da produção, revisão e reescrita, o aluno é convidado a dar continuidade em sua produção. Sendo assim: "A produção, nesse caso, surge de um processo contínuo de ensino/aprendizagem" (SERCUNDES, 1997, p. 83). Portanto, nessa concepção, o trabalho do aluno não fica restrito ao ato de produzir para cumprir o que foi pedido pelo professor e receber uma determinada nota, há uma continuação, o aluno escreverá para alguém, e como está escrito nesse comando o seu texto tem a finalidade de ser integrado em um livro ou blog.

\subsection{Quanto ao papel do sujeito produtor}

Os papéis de sujeito produtor foram encontrados apenas na segunda unidade, determinando-o como argumentista. O sexto comando do LD ilustra a condição:

\section{AGORA É A SUA VEZ}

Vamos fazer, em grupo, histórias em quadrinhos?

Planejamento do texto

- Desenhem uma ou duas personagens com características bem-definidas. Se possível, consultem os livros indicados na abertura desta unidade, na seção Fique ligado! Pesquise!

- Coloquem-se no papel de um argumentista e criem o texto da história. Lembrem-se: a linguagem empregada nos diálogos entre personagens é parecida com a que usamos no dia a dia. 
Assim, vocês podem usar a variedade linguística que normalmente usam quando falam com os colegas.

- Façam um rascunho da história: em quadrinhos e na sequência correta, esbocem as personagens e escrevam suas falas, seus pensamentos e as legendas, além de onomatopeias, se houver.

- Numa folha de papel sulfite, desenhem os quadrinhos, as personagens e os balóes, dispondo-os em sequência, de acordo com a história que criaram. Escrevam as falas e os pensamentos, as onomatopeias e interjeições, se houver. Lembrem-se: as falas são escritas em letras de fôrma, maiúsculas; depois das onomatopeias e interjeições, usa-se o ponto de exclamação.

- Complete os quadrinhos com desenhos que mostrem o lugar em que acontece a história. no último.

- Acertem os detalhes finais: coloquem o título da história no $1^{\circ}$ quadrinho e a palavra fim

(CEREJA; COCHAR; 2015, p. 122).

Nesse comando, o aluno criará uma história em quadrinhos e se posicionará como um argumentista: “Coloquem-se no papel de...”. Essa condição foi encontrada apenas nesse comando do livro didático, nos outros comandos, como exemplo, os alunos são solicitados a escrever contos maravilhosos ou artigo de opinião, mas não está explícito que eles se colocarão no papel de contista ou articulista.

A falta desse papel marcado pode afetar a produção do aluno, pois pode não se constituir como sujeito do seu texto. Ao trabalhar o gênero, é preciso que o aluno se constitua como enunciador desse texto, compreendendo seu papel de produtor. Sempre que escrevemos nos constituímos como enunciador de um discurso. Esse enunciador, quando constrói seu discurso, já tem conhecimento de discursos anteriores, tomando-os para si e reelaborando seu discurso próprio. Nesse sentido, é preciso "Desenvolver no aluno a capacidade de se assumir como autor, como sujeito do seu dizer" (MENEGASSI, 2016, p. 202).

\subsection{Quanto aos gêneros solicitados}

Dentro de cada unidade, foi verificado o gênero a ser produzido pelo aluno. No total, foram verificados 14 comandos, com os seguintes gêneros:

Quadro 5. Levantamento dos gêneros solicitados nos comandos.

\begin{tabular}{|c|l|c|}
\hline UNIDADE & \multicolumn{1}{|c|}{ CAPÍTULOS } & GÊNEROS \\
\hline \multirow{3}{*}{1} & CAPÍTULO 1: Era Uma Vez & Conto maravilhoso \\
\cline { 2 - 3 } & CAPÍTULO 2: Pato aqui, pato acolá & Conto maravilhoso \\
\cline { 2 - 3 } & CAPÍTULO 3: Ó princesa! Jogue-me suas... & Conto maravilhoso \\
\hline \multirow{3}{*}{2} & CAPÍTULO 1: O fazendeiro da cidade & HQ \\
\cline { 2 - 3 } & CAPÍTULO 2: Entre irmãos & HQ, Cartazes \\
\cline { 2 - 3 } & CAPITULO 3: Ensaios da vida & HQ \\
\hline \multirow{3}{*}{3} & CAPÍTULO 1: No frescor da Inocência & Relato Pessoal \\
\cline { 2 - 3 } & CAPÍTULO 2: O preço de pensar diferente & Diário \\
\cline { 2 - 3 } & CAPITULO 3: O eu que existe em mim & E-mails \\
\cline { 2 - 3 } & CAPITULO 3: O eu que existe em mim & Comentário em blog ou site \\
\hline & CAPÍTULO 1: Asas da Liberdade? & Artigo de Opinião \\
\hline
\end{tabular}




\begin{tabular}{|l|l|c|}
\hline \multirow{3}{*}{4} & CAPÍTULO 2: A natureza pede socorro & Artigo de Opinião \\
\cline { 2 - 3 } & CAPÍTULO 3: Natureza no museu & Exposição oral \\
\cline { 2 - 3 } & CAPÍTULO 3: Natureza no museu & Cartaz \\
\hline
\end{tabular}

Fonte: Elaboração das autoras.

A partir do exposto, verifica-se o total de 14 produções solicitadas aos alunos no livro do 6. ${ }^{\circ}$ ano. O aluno é levado a produzir Contos Maravilhosos (3 comandos); HQ (3 comandos); Cartazes ( 2 comandos); Relato Pessoal (1 comando); diário (1 comando); e-mails (1 comando); Comentário em blog ou site (1 comando); Artigo de Opinião (2 comandos); Exposição oral (1 comando).

Destaca-se o décimo segundo comando do LD para ilustrar a condição:

AGORA É A SUA VEZ uma delas.

Há, a seguir, duas propostas para a produção de um artigo de opinião. Leia-as e escolha

1. De acordo com o artigo III da Declaração dos Direitos dos Animais, nenhum animal deve ser submetido a maus-tratos e atos cruéis; se sua morte é necessária, deve ser instantânea, sem dor nem angústia. Na sua opinião, é possível conciliar as experiências cientificas com o que recomenda esse artigo? O que precisaria ser feito para isso?

2. Estudos voltados à substituição de animais nos testes de laboratório estão em andamento. Enquanto essa substituição não ocorre, as pesquisas atuais direcionadas à saúde humana deveriam ser abandonadas? Qual é a sua opinião sobre isso?

Depois de escolher uma das propostas, tome uma posição a respeito do assunto e preparese para redigir seu texto. Ele será lido por colegas da sua classe e de outros anos, por famílias, amigos e visitantes da mostra Se é meio ambiente estou o meio, proposta no capítulo Intervalo desta unidade.

Se quiser, envie seu texto a um jornal da cidade ou a um fórum de debates de um dos provedores da internet. Ou, ainda, hospede-o em um blog da classe.

(CEREJA; COCHAR; 2015, p.234 e 235)

O gênero solicitado é o "artigo de opinião": "duas propostas para a produção de um artigo de opinião”. Em todos os comandos do LD, há o gênero definido para o aluno. O trabalho com o gênero possibilita ao aluno apropriar-se de textos que empregará socialmente, fato que justifica sua presença no material didático. Trata-se de um comando que dialoga com a concepção de escrita como trabalho, já que o texto será lido "por colegas da sua classe e de outros anos, por famílias, amigos e visitantes da mostra” e ainda poderá ser publicado no "jornal da cidade ou a um fórum de debates de um dos provedores da internet. Ou, ainda, hospede-o em um blog da classe”.

Os comandos, de forma geral, trazem as condições de produção. Em maior número tratam das condições: a) Se tenha o que dizer; b) Se tenha uma razão para dizer; c) Se tenha para quem dizer e e) Se escolham as estratégias para realizar (a), (b), (c) e (d). Em menor número a condição: d) locutor se constitua como tal. Com isso, o aluno é levado a produzir um discurso 
adequado e completo, pois, conhecendo todos esses elementos, consequentemente, ele escreverá sabendo para quê e porquê escreve.

\section{Considerações finais}

A análise dos comandos de escrita do livro didático permitiu constatar a presença das condições de produção dos textos: "Se tenha o que dizer (tema)" apresentou-se em todos os 14 comandos; "Se tenha uma razão para dizer" (finalidade), apresentou-se 12 vezes nos comandos; "Se tenha para quem dizer (interlocutor)", aparece 11 vezes; "d) Locutor se constitua como tal (papel do sujeito - escritor)", apresentou-se apenas em 1 comando; "e) Se escolham as estratégias para realizar (a), (b), (c) e (d) (gênero)", apareceu nos 14 comandos do LD.

Com base nesse levantamento, observa-se que há a maior presença das condições: a) tema e e) gênero, isso significa que o LD se preocupa em situar o aluno na construção temática do texto, assim como no gênero a ser elaborado. Faz-se necessário, no entanto, ressaltar a necessidade de presença de todas as condições em todos os comandos para que se efetive uma escrita em âmbito social e significativo.

As condições direcionam o aluno durante as etapas da escrita, conhecendo-as, consequentemente, realizarão um discurso mais adequado, sendo capazes de utilizar a escrita com eficácia, assumindo a palavra, inclusive, sendo ela por escrito, transformando-se em sujeitos participantes e ativos das diferentes formas de comunicação. Durante a análise, observou-se a ausência das condições em alguns comandos, o que pode refletir na escrita do aluno. O ideal, de acordo com as teorias de ensino, citadas ao longo do texto, é que todas elas sejam evidenciadas ao aluno no decorrer do comando, pois, assim, ele terá condições reais de produção, constituindo-se como autor de seu texto.

Para futuras pesquisas sugere-se a reelaboração dos comandos de escrita, pensando-se nas condições de produção que estavam ausentes no momento da análise, fazendo com que os alunos tenham o contato real com cada uma delas, escrevendo com objetivos claros e com interlocutores marcados.

\section{Referências}

CEREJA, W.; COCHAR, T. Português Linguagens, $6^{\circ}$ ano. 9. ed. São Paulo: Editora Saraiva. 2015 
ESPER, D. S.; MENEGASSI, R. J. Caracterizando os processos de revisão e reescrita no Ensino Fundamental I. Relatório de Pesquisa de Iniciação Científica. Universidade Estadual de Maringá: UEM, 2011.

FRANZOI, R. C. Manifestações do Interlocutor nas Produções Textuais Escritas no Ensino Fundamental. 2009. 123f. Dissertação (Mestrado em Letras) - Universidade Federal de Maringá, Maringá, 2009.

FUZA, A. F; MENEGASSI, R. J. Revisão e reescrita de textos a partir do gênero textual conto infantil. Diálogo das Letras, Pau dos Ferros, v. 01, n. 01, p. 41-56, jan./jun. 2012. Disponível em: http://periodicos.uern.br/index.php/dialogodasletras/article/view/222/0. Acesso em: 10 dez. 2018.

FUZA, A. F.; MENEGASSI, R. J. A finalidade da escrita no livro didático: marcas no gênero discursivo. Uniletras, Ponta Grossa, v. 30, n. 2, p. 317-333, jul./dez. 2008 Disponível em: http://www.uepg.br/uniletras.

GERALDI, J. W. Da redação a produção de textos. In: GERALDI, J. W, CHELLI, B. Aprender e ensinar com textos de alunos. São Paulo: Cortez, 1997.

GERALDI, J. W. O Texto na Sala de Aula. 4.ed. São Paulo: Ática, 2006.

GRIBEL, C. Minhas férias, pula uma linha, parágrafo. Ilustrações de Jean Claude Alphen. São Paulo: Salamandra, 2013.

LÜDKE, M.; ANDRÉ, M.E.D.A. Pesquisa em educação: abordagens qualitativas. São Paulo: EPU, 1986.

MENEGASSI, R. J. A Revisão de textos na formação docente inicial. In: GONÇALVES, A. V.; BAZARI, M. Interação, Gêneros e Letramento: A (re)escritaem foco. São Paulo: Pontes Editores, 2013, p. 105-131.

MENEGASSI, R. J. A escrita como trabalho. In: JORDÃO, C. M (org). A Linguística Aplicada no Brasil: rumos e passagens. Campinas: Pontes Editores, 2016. p. 193-230.

MOTERANI, N. G.; MENEGASSI, R. J. Aspectos lingüísticos- discursivos na revisão textualinterativa. Trabalhos em Linguística Aplicada. Campinas, n(52.2): 217-237, jul./dez. 2013.

PEREIRA, R. F. Produção de textos na escola. In: CECCANTINI, J. L. C. T.; PEREIRA. R. F.; ZANCHEITA. JR., J. (orgs). Pedagogia cidadã: cadernos de formação: Língua Portuguesa. São Paulo: Unesp/Pró-Reitoria de Graduação. 2004, p. 101-111.

SERCUNDES, M. M. I. Ensinando a escrever. In: GERALDI, J. W.; CITELLI, B. Aprender e ensinar com textos de alunos. v. 1. São Paulo: Cortez, 1997, p. 75-97.

VAL, M. G. C. Atividades de produção de textos escritos em livros didáticos de $5^{\mathrm{a}}$ a $8^{\mathrm{a}}$ series do ensino fundamental. In: ROJO, R.; BATISTA, A. A. G. Livro Didático de Língua Portuguesa: letramento e cultura da escrita. Campinas: Mercado de Letras, 2003, p. 125-152. 
Recebido em 17 de dezembro de 2018. Aceito para publicação em 21 de maio de 2019. 